\title{
English Language Teachers' Ideology of ELT Assessment Literacy
}

\author{
Badia Hakim \\ English Language Institute (ELI), King Abdulaziz University, Saudi Arabia \\ E-mail: badiahakim82@gmail.com
}

Received: 20-09- 2015

Accepted: $30-10-2015$

Published: 31-10-2015

doi:10.7575/aiac.ijels.v.3n.4p.42

URL: http://dx.doi.org/10.7575/aiac.ijels.v.3n.4p.42

\begin{abstract}
Deep understanding, clear perception and accurate use of assessment methodology play an integral role in the success of a language program. Use of various assessment techniques to evaluate and improve the performance of learners has been the focal point of interest in the field of English Language Teaching (ELT). Equally researchers are interested in evaluating teachers' awareness and improved performance in relation to the learners' performance. The current study was designed to investigate the teachers' awareness level and way of practicing the assessment tools for the better learning of the students in the English Language Institute (ELI), King Abdulaziz University. The research was based on the perceptions and feedback of 30 female language instructors from 5 different nationalities with varying qualifications and ELT experience working at ELI. Quantitative method was followed. A questionnaire was developed by the researcher was administered to the instructors. Descriptive statistics was used to analyze the data. The results revealed that all the participants had a clear knowledge about the use of assessment tools. It was also found that the teachers' perceptions about assessment tools are least affected by their span of teaching experience. Another noteworthy finding was the poor practicing techniques of the instructors who were well aware of the assessment techniques.
\end{abstract}

Keywords: KAU - ELI, Language Assessment Literacy (LAL), Assessment Literacy Program (ALP)

\section{Introduction}

Assessment is one of the most important and challenging features of English Language Teaching (ELT) and its implication demands a lot of accuracy and clear perception. Malone (2011) stated that teaching and assessment are two interrelated factors in English Language Teaching (ELT) that play a supportive role for each other. Experimental approach to improve and innovate the testing and assessment techniques has been globally adapted. Consequently, standard of ELT is greatly affected by the teachers' assessment literacy that has led to a progressive era of latest research on ELT assessment.

Knowing the fact that teachers are the key assessors inside a classroom, their role to use received feedback about the effective teaching techniques is significant. As identified by O'Malley and Valdez Pierce (1996, p. 3, as cited in ReaDickins, 2001), there are certain main aims of any assessment that are enlisted here:

1. Placement of students,

2. Screening and identification of any issues,

3. Replacement or promotion,

4. Checking the rate of students' progress,

5. Appraisal of the existing educational program, and

6. Diagnosing probable liabilities of the program.

Llosa (2011) stated that clear perception of ELT assessment opens a doorway for teachers to set new challenging standards and make serious efforts to bring a balance between teaching and aim of the set assessment technique. The same idea was supported by Frey and Schmitt (2007) who declared the formative assessment as an effective tool to align the teaching techniques to the level of learners' needs.

Mertler and Campbell (2005) introduced an assessment tool known as Assessment Literacy Inventory (ALI) in order to evaluate the teachers' assessment literacy. It is vital to run certain awareness programs that provide knowledge about the assessment techniques and methodology to the teachers before they start their career, but usually such programs are superficial, having no focus on the core issues (Kahl et al., 2012). In order to enhance the quality of Assessment Literacy Programs (ALP) and fulfill the requirements of the teaching staff by focusing on the ALP agenda, the following outline can be proposed (Table 1): 
Table 1. ALP agenda

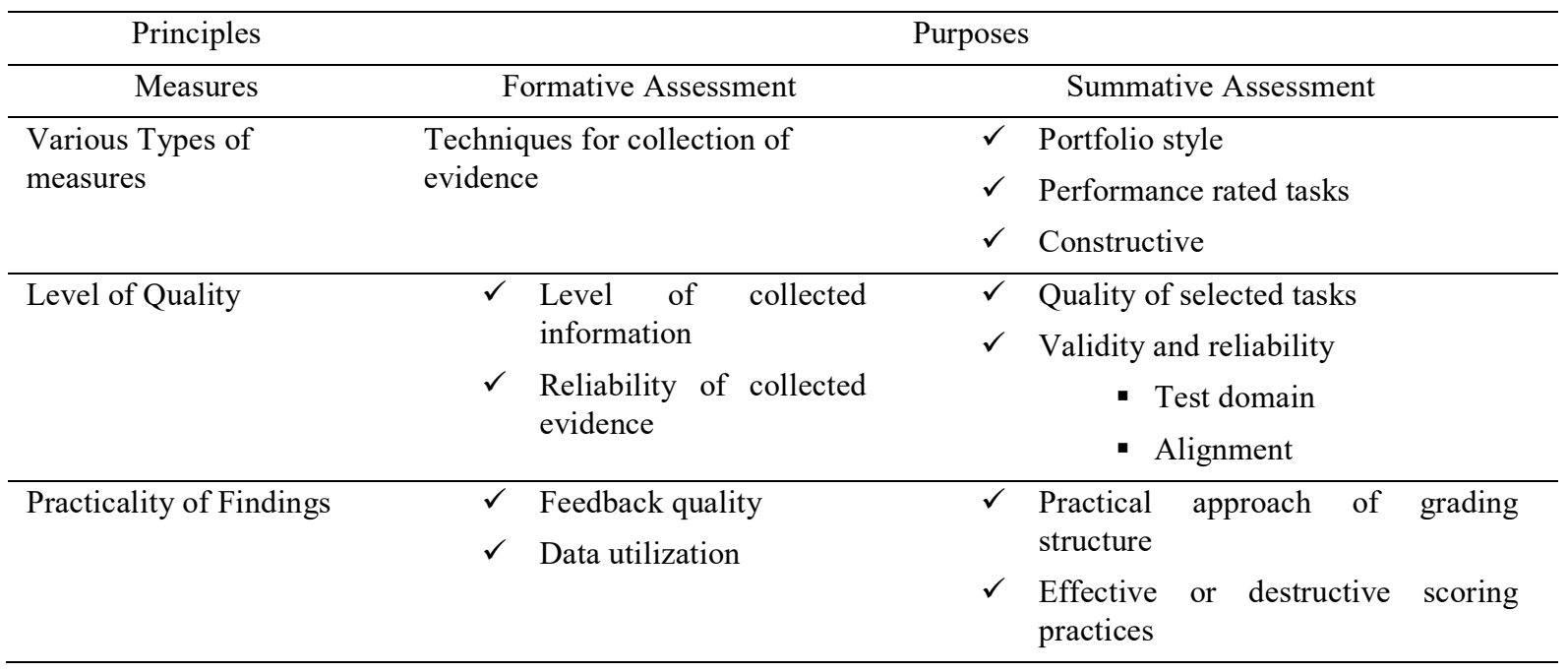

ALP agenda mainly address the techniques of transmitting knowledge, improvement of required skills and facing the challenges of various proficiencies that comprise the main components of any ALP.

1.1 Objective

Assessment literacy is a significant constituent of any teacher training or educational program. The current study aimed to investigate English language teachers' ideology of ELT assessment literacy. In other words, the objective of the study was to examine the assessment-related perceptions and practices of teachers. The following research question was posed in order to achieve the objective of the study:

\subsection{Research question}

How do teachers with different levels of teaching experience differ in their assessment ideology?

\section{Literature review}

Various case studies were conducted by different educationists in order to explore the beliefs of teachers towards the practical use of assessment. In a case study, Sikka et al. (2007) investigated the assessment literacy of 69 primary school teachers by using survey method. They recommended embedding practical aspects of assessment techniques in teacher training programs. The focus of another case study by Volante and Fazio (2007) was mainly on assessment literacy of junior teachers. As their findings indicated, the summative assessment technique is more successful and productive in comparison with the formative assessment method.

A case study by Mertler (2003) was conducted in Ohio in order to compare the difference between the impact of traditional assessment methods and the alternative innovative assessment techniques. The findings indicated that participants from varying grade levels with different years of teaching experience used different assessment techniques according to the needs of the learners. An interesting finding of this study was the alternative use of innovative assessment techniques by the elementary level teachers as compared with the middle and high school level teachers. This reflected upon the fact that use of assessment techniques by the teachers from different grade levels depends upon the learners' needs and level of knowledge.

Following almost the same ideology, another case study was based on a big number of teachers' multiple assessment techniques used for students from various levels. The findings of this study by Zhang and Burry-Stock (2003) indicated the preferred use of objective type of tests as the preferred assessment technique and showed a serious concern of the participants over aligning the quality of assessment with an increase in grade level of the students. A case study by Sahinkarakas (2012) investigated the role of teaching experience on teachers' perceptions of language assessment. She used the metaphor technique in order to compare the assessment related perceptions of the language teachers with varying levels of teaching experience. The analysis of the grouped themes indicated the following categories:

1. Formative assessment approach,

2. Summative assessment approach,

3. Assessment as a provoking approach, and

4. Assessment as a self- efficacy approach.

A case study was conducted by Shim (2009) on the language teachers about their ideology and practical approach towards the types and use of different assessment techniques. Participants responded to different questionnaires and gave their feedback in short interview sessions as well. The assessment literate participants indicated the fact that assessment techniques and practices are greatly influenced by certain factors that are in the control of the language 
teachers, classroom strength, teaching loads, centralized departmental political attitudes, and also the financial support the language program receives. A commonly noticed factor is the gap between the teachers' perceptions about assessment and their actual practical approach (Muñoz et al., 2012). Teachers' survey responses and focus group interviews were used by Qassim (2008) in order to test the factors affecting the teachers' beliefs about assessment. The findings reflected the negative influence of teaching time, curriculum workload, and strength of a class on the constructive output of different assessment styles. In the same study another noteworthy recommendation by the participants was to provide the facility of assessment-related training courses and workshops for the faculty.

Language assessment courses play a vital role in enhancing the assessment literacy among language teachers. The positive impacts of training programs on teachers' self-confidence and their awareness about assessment skills was also identified by Lukin et al. (2004).

Another important study in almost the same area of interest was conducted by Malone (2013). This study was focused on the content of a tutorial which was developed to promote foreign language instructors' knowledge about assessment basics. Feedback was collected from all study participants (44 language instructors and 30 language testers) in the U.S. Results of the study indicated a clear difference in the opinions of language testers and language educators regarding the requirements of the significant technical information about assessment. These findings have shed light on the fact that instructors' perceptions about assessment differ from their practical approach in the same field, which should be seriously considered by the designers of the assessment training programs while developing the tutorials or materials. Importance of enhancing the language assessment literacy among in-service teachers was investigated by Scarino (2013). She stated the importance of integrating the language assessment knowledge with understanding, culture and learning trends of a language. Moreover, a great stress was put forth on the test users and test developers to become aware of assessment procedures in order to infer and gauge their own assessment practical approach.

In response to the mounting and gradually developing field of language assessment and testing, Taylor (2013) laid significant stress on gaining awareness about the development and maturation of assessment literacy that is a prerequisite to understand the fundamental principles of assessment practices. Indeed, developing a clear understanding about the various aspects of language assessments is utterly important for language testers and test developers.

Teachers' perceptions about the assessment literacy and their level of understanding about the practical application of the same theme have a great influence on their mode of teaching and assessing their students. The striking fact is that an immense amount of research work in the ELT assessment awareness field clearly indicates the relative lack of practical work in Language Assessment Literacy (LAL). The current study was based on the idea to find out the teachers' awareness level and way of practicing the assessment tools for the better learning of the students.

\section{Methodology}

In order to conduct this study, an obtrusive data collection method was used. A structured questionnaire (Appendix A) was distributed among teachers from three different English language teaching experience categories. The questions were mainly structured around the concept of prompting the teachers' beliefs and their practical approach towards LAL. The collected responses were tabulated.

\subsection{Sample and sampling}

The participants of the study were chosen by convenience sampling and these were 30 female language instructors from 5 different nationalities with varying qualifications and ELT experience working at the English Language Institute (ELI), King Abdulaziz University. As for their educational levels, 13 participants had Bachelor's degrees with (CELTA/DELTA), 15 had Master's degrees with (CELTA/DELTA) while 2 were PhD students in English Linguistics. All the 30 participants of the study were placed in three groups based on their teaching experience.

Table 2. Classification of participants

\begin{tabular}{cccc}
\hline Groups & $\begin{array}{c}\text { Group A - Novice } \\
\text { Teachers }\end{array}$ & $\begin{array}{c}\text { Group B- Medium } \\
\text { Experienced }\end{array}$ & Group C - Experienced \\
\hline Teaching Experience & $0-3$ years & $5-10$ years & 10 years + \\
$\begin{array}{c}\text { Frequency (Percentage) } \\
\text { of Participants }\end{array}$ & $10-(33 \%)$ & $15(50 \%)$ & $5(17 \%)$ \\
\hline
\end{tabular}

Half the participants had moderate teaching experience levels, a third fell into the category of novice instructors whereas one in six was experienced. 


\subsection{Instrument}

A questionnaire was developed by the researcher, validated by a panel of experts and distributed among the selected participants. The elicited data were compiled and analyzed. The internal consistency of the instrument turned out to be unimpressive (Cronbach's alpha $=0.50$ ) which could be attributed to the fact that the participants did not have consistent ideologies of ELT assessment.

\section{Results and Discussion}

IBM SPSS (Version 21) was used to analyze the data. All the collected responses were coded and keyed in. Descriptive statistics methods including frequency and percentage were used to find out if any different trends existed between the instructors from three teaching experience categories. Table 3 summarizes the findings of the study. The results are reported as Frequency (Percentage) of the participants who marked the response.

Table 3. Assessment ideologies of teachers with different teaching experience levels $(n=30)$

\begin{tabular}{|c|c|c|c|c|c|c|c|c|c|}
\hline \multirow[t]{2}{*}{ Language assessment ... } & \multicolumn{3}{|c|}{ Novice $(\mathrm{n}=11)$} & \multicolumn{3}{|c|}{ Medium $(n=14)$} & \multicolumn{3}{|c|}{ Experienced $(n=5)$} \\
\hline & $\mathrm{D}$ & $\mathrm{A}$ & SA & $\mathrm{D}$ & A & SA & $\mathrm{D}$ & A & SA \\
\hline $\begin{array}{l}\text { 1. should focus on a blend of } \\
\text { skills and language } \\
\text { components }\end{array}$ & 0 & $8(80 \%)$ & $2(20 \%)$ & 0 & $11(73 \%)$ & $4(27 \%)$ & 0 & $1(20 \%)$ & $4(80 \%)$ \\
\hline $\begin{array}{l}\text { 2. impacts the way students } \\
\text { study and do assignments }\end{array}$ & 0 & $6(60 \%)$ & $4(40 \%)$ & 0 & $10(68 \%)$ & $5(32 \%)$ & 0 & $3(60 \%)$ & $2(40 \%)$ \\
\hline 3. should be fair and valid & 0 & $1(10 \%)$ & $9(90 \%)$ & 0 & $4(27 \%)$ & $11(73 \%)$ & 0 & 0 & $5(100 \%)$ \\
\hline $\begin{array}{l}\text { 4. should use rubrics for } \\
\text { assessing the language skills }\end{array}$ & 0 & $2(20 \%)$ & $8(80 \%)$ & 0 & $6(40 \%)$ & $9(60 \%)$ & 0 & $1(20 \%)$ & $4(80 \%)$ \\
\hline $\begin{array}{l}\text { 5. } \\
\text { should result in consistent } \\
\text { across the levels }\end{array}$ & 0 & $4(40 \%)$ & $6(60 \%)$ & 0 & $5(32 \%)$ & $10(68 \%)$ & 0 & $2(40 \%)$ & $3(60 \%)$ \\
\hline $\begin{array}{l}\text { 6. should have an assessment } \\
\text { outline that students' } \\
\text { learning outcome matches } \\
\text { with }\end{array}$ & 0 & $2(20 \%)$ & $8(80 \%)$ & 0 & $2(13 \%)$ & $13(87 \%)$ & 0 & $1(20 \%)$ & $4(80 \%)$ \\
\hline $\begin{array}{l}\text { 7. should align with course } \\
\text { objective }\end{array}$ & 0 & $2(20 \%)$ & $8(80 \%)$ & 0 & $2(13 \%)$ & $13(87 \%)$ & 0 & 0 & $5(100 \%)$ \\
\hline $\begin{array}{l}\text { 8. should be structured to } \\
\text { evaluate the students' level } \\
\text { of achievement in various } \\
\text { language components }\end{array}$ & 0 & $3(30 \%)$ & $7(70 \%)$ & 0 & $6(40 \%)$ & $9(60 \%)$ & 0 & $2(40 \%)$ & $3(60 \%)$ \\
\hline $\begin{array}{l}\text { 9. should help to analyze the } \\
\text { suitability of the included } \\
\text { components }\end{array}$ & 0 & $4(40 \%)$ & $6(60 \%)$ & 0 & $6(40 \%)$ & $9(60 \%)$ & 0 & $2(40 \%)$ & $3(60 \%)$ \\
\hline $\begin{array}{l}\text { 10. should engage students in } \\
\text { peer and self-assessment }\end{array}$ & $8(80 \%)$ & $2(20 \%)$ & 0 & 0 & $7(47 \%)$ & $8(53 \%)$ & 0 & $1(20 \%)$ & $4(80 \%)$ \\
\hline $\begin{array}{l}\text { 11. should provide information } \\
\text { for teachers based on which } \\
\text { students can improve }\end{array}$ & 0 & $2(20 \%)$ & $8(80 \%)$ & 0 & $4(27 \%)$ & $11(73 \%)$ & 0 & 0 & $5(100 \%)$ \\
\hline $\begin{array}{l}\text { 12. should start with a list of } \\
\text { specifications }\end{array}$ & $6(60 \%)$ & $3(30 \%)$ & $1(10 \%)$ & $6(40 \%)$ & $4(27 \%)$ & $5(33 \%)$ & 0 & 0 & $5(100 \%)$ \\
\hline
\end{tabular}

Key: $\quad$ Novice (0-3 years), Medium (5-10 years), Experienced (10 years + );

D: disagree, A: agree, SA: strongly agree

According to the results, overall the participants in all three categories of teaching experience marked the responses that indicated their adequate understanding of ELT assessment. The instructors, regardless of their different teaching experience levels, generally valued the important features in language assessment. The reason behind these findings could be some ongoing in-house assessment awareness training programs and workshops in the institute. This point has been stated very well by Taylor (2009), who argues:

Assessment literacy demands a training that brings a smooth blend of assessment technical awareness, theoretical understanding, useful practical skills, and clear concepts. All these components well balanced but strongly 
contextualized with the clear role, practical approach and function of assessment in the field of education. At a closer look, the findings in Table 3 clearly indicate a trend that as the instructors' experience increases, so does the strength of their ideologies. Interestingly the findings of the research strongly reflect that in comparison with the two other groups, experienced instructors value:

- $\quad$ integrated assessment more highly (Item 1);

- $\quad$ fair and valid assessment (Item 3);

- $\quad$ alignment of assessment with course objective (Item 7);

- $\quad$ peer- and self-assessment (Item 10);

- $\quad$ diagnostic power of formative assessment (Item 11); and

- test construction based on a set of specifications (Item 12).

The difference was more noticeable in the case of peer- and self-assessment (Item 10) as well as importance of test specifications (Item 12). As per engaging students in peer- and self-assessment, a majority (80\%) of the novice instructors surprisingly disagreed, about half (47\%) the moderately experienced instructors agreed whereas a majority of the experienced instructors $(80 \%)$ strongly agreed with this ideology. Almost a similar trend could be observed for the last item, importance of setting test specifications before assessment. While a majority of novice (60\%) and moderately experienced (40\%) instructors surprisingly disagreed with this item, all the experienced instructors were of the idea that assessment must begin by listing specifications. These results suggest that the higher the instructors' experience, the clearer their understanding of assessment components and testing plan.

\section{Conclusion and Implications}

Rea-Dickens (2004) regards language teachers as the agents in the assessment process. The role of language teacher holds a prime importance when it comes to the intelligent use of assessment techniques as a learning tool (Rea-Dickens, 2004). The present researcher tried to reflect on the theme of Language Assessment Literacy (LAL) in relation to instructors' teaching experience because this topic is gaining popularity in the field of ELT assessment and testing research. In this study the main aim of the researcher was to explore a group of instructors' language assessment ideology and to see whether teaching experience leads to differences in language instructors' assessment ideologies.

Research findings clearly indicate that the instructors from all the three experience groups had a general awareness of Language Assessment Literacy (LAL), and they had an understanding of the basic assessment techniques and ways of practicing them for the benefit of their learners. In addition to this, a significant finding is teaching experience seems to play a role in teachers' assessment perceptions and practices. Noticeably, experienced instructors had a deeper understanding of LAL and they adapted their assessment practices in a fruitful manner. In the case of certain items a considerable proportion of novice instructors failed to reflect their awareness of practical assessment techniques. Approaching the findings of the study from practical point of view leads to state that this study has tried to put forth some academic ideology by broadening the spectrum of perception and practice in the field of language assessment and testing. Based on the findings of this study, it seems logical to conclude that particularly novice language teachers should be encouraged to strengthen their assessment literacy through training courses that aim at giving them a clear and deep understanding of effective assessment components, concepts, ideology and practices. Assessment literacy can be enhanced by different techniques. For example, training courses, reading articles, tutorials, workshops, discussion groups, online resources are some of the most commonly practiced techniques.

Assessment practices that are suitable and aligned with the needs of the learners always act as boosters for learning and teaching. It is essential that language teachers familiarize with both summative and formative assessment techniques in order to be able to implement the appropriate assessment techniques successfully and efficiently in their classrooms. Almost all the participants in this study recognized formative or ongoing assessment as an effective form of assessment. Participants also asserted the important of the standard of assessment and its appropriateness to the course objectives, age and proficiency level students.

Apparently use of self- and peer-assessment is challenging for less experienced language instructors. In the context of ELI, peer assessment is introduced as a peer review in writing courses. Most of the novice instructors were not comfortable with these forms of assessment techniques. This could be due to certain factors like time constraints for curriculum pace, big number of students in an average class, and lack of confidence among students. These factors are reported to have a negative impact on different assessment techniques that are practiced by language teachers especially those who were teaching beginners or elementary level of students. By contrast, more experienced instructors accepted peer review and self-assessment techniques are helpful. According to them they bring an idea of peer learning and provide an incentive to learners to enhance their knowledge about the main aim and structure of assessment. The idea of self-assessment and peer review in language learning arena brings more chances of self-corrections because it provides an opportunity for learners to reflect on their own and others' performance critically. Learners should be encouraged to use this technique in a constructive manner to enhance their learning standards by giving related feedback. Practically this assessment technique increases motivation level among students. However, best results can only be achieved by careful and skilled handling; that is why, mostly novice or medium experienced teachers avoid using this technique. In this study, a remarkable proportion of the novice and moderately experienced instructors did not assign high scale ratings to self- and peer-assessment techniques. 
A significant tool that can optimize assessment designing and quality as a base for test builders is a list of specifications. Apart from having a set assessment designed by the management, sometimes at a local and internal class level, teachers may use such tools to design their own mini assessments or class quizzes in alignment to the course objectives. The same idea was confirmed by Fives and DiDonato-Barnes (2013) who argued that such practices help to enhance the validity of the test or assessment by aligning the course content with assessment objectives.

Finally, use of assessment results can be a very effective and practical tool for language teachers in order to gauge the performance of their learners. Assessment results play a vital role in the development of both teachers and learners by providing a way for self-reflection and critical analysis of the performance.

\section{References}

Fives, H., \& DiDonato-Barnes, N. (2013). Classroom test construction: The power of a table of specifications. Practical Assessment, Research \& Evaluation, 18(3), 1-7.

Frey, B. B. \& Schmitt, V. L. (2007). Coming to terms with language assessment. Journal of Advanced Academics, $18(3), 402-423$.

Jeong, H. (2013). Defining assessment literacy: Is it different for language testers and non-language testers? Language Testing, 30(3), 345-362.

Kahl, S. R., Hofman, P. \& Bryant S. (2012). Assessment literacy standards and performance measures for teacher candidates and practicing teachers. Assessment.

Llosa, L. (2013). Standards-based classroom assessments of English proficiency: A review of issues, current developments, and future directions for research. Language Testing, 28(3), 367-382.

Lukin, L. E., Bandalos, D. L., Eckhout, T. J. and Mickelson, K. (2004). Facilitating the development of assessment literacy. Educational Measurement: Issues and Practice, 23(2), 26-32.

Malone, M. E. (2011). Assessment literacy for language educators. http://www.cal.org/resources/digest/assessmentliteracy-for-language-educators.html

Malone, M. E. (2013). The essentials of assessment literacy: Contrasts between testers and users. Language Testing, 30(3), 329-344.

Mertler, C. A., \& Campbell, C. (2005). Measuring teachers' knowledge \& application of classroom assessment concepts: Development of the "Assessment Literacy Inventory". Online Submission. Paper presented at the Annual Meeting of the American Educational Research Association (Montreal, Quebec, Canada, Apr 11 to 15, 2005)

Mertler, C. A. (2003). Preservice versus inservice teachers' assessment literacy: Does classroom experience make a difference? Paper presented at the Annual Meeting of the Mid-Western Educational Research Association, Columbus, $\mathrm{OH}$.

Muñoz, A. P., Palacio, M., \& Escobar, L. (2012). Teachers' beliefs about assessment in an EFL context in Colombia. Profile: Issues in Teachers' Professional Development, 14(1).

O'Loughlin, K. (2013). Developing the assessment literacy of university proficiency test users. Language Testing, 30(3), 363-380.

Pill, J., \& Harding, L. (2013). Defining the language assessment literacy gap: Evidence from a parliamentary inquiry. Language Testing, 30(3), 381-402.

Popham, W. J. (2009). Assessment literacy for teachers: Faddish or fundamental?. Theory into Practice, 48, 4-11.

Qassim, J. A. S. (2008). Teachers' perceptions of current assessment practices in public secondary schools in the state of Qatar. Unpublished doctoral dissertation. University of Hull, Qatar.

Rea-Dickins, P. (2001). Mirror, mirror on the wall: identifying processes of classroom assessment. Language Testing, 18 (4), 429-462.

Rea-Dickens, P. (2004). Understanding teachers as agents of assessment. Language Testing, 21(3), 249-258.

Sahinkarakas, S. (2012). The role of teaching experience on teachers' perceptions of language assessment. Procedia Social and Behavioral Sciences, 47, 1787-1792.

Scarino, A. (2013). Language assessment literacy as self-awareness: Understanding the role of interpretation in assessment and in teacher learning. Language Testing, 30(3), 309-327.

Shim, K. N. (2009). An investigation into teachers' perceptions of classroom-based assessment of English as a foreign language in Korean primary education. Unpublished doctoral dissertation. University of Exeter, Exeter.

Sikka, A., Nath, J. L., \& Cohen, M. D. (2007). Practicing teachers' beliefs and uses of assessment. International Journal of Case Method Research \& Application, 3, 240-253.

Simpson-Beck, V. (2011). Assessing classroom assessment techniques. Active Learning in Higher Education, $12(2), 125-132$. 
Stiggins, G. (1997). Student centered classroom assessment. Upper Saddle River, NJ: Prentice Hall. Susuwele-Banda, W. J. (2005). Classroom assessment in Malawi: Teachers' perceptions and practices in mathematics. Unpublished doctoral dissertation. Virginia Polytechnic Institute and State University, Virginia.

Taylor, L. (2013). Communicating the theory, practice and principles of language testing to test stakeholders: Some reflections. Language Testing, 30(3), 403-412.

Taylor, L. (2009). Developing assessment literacy. Annual Review of Applied Linguistics, 29, 21-36.

Volante, L. \& Fazio, X. (2007). Implications for teacher education reform and professional development. Canadian Journal of Education, 30(3), 749-770.

\section{Appendix A: Questionnaire}
NA: Not Applicable
D: Disagree
A: Agree
SA: Strongly agree

1. Assessment should be focused on a blend of skills and language components.

2. Assessment impacts the way students study and do assignments.

3. Assessment should be fair and valid.

4. Use of rubrics for assessing the language skills is a good idea.

5. In response to assessment components students' success rate should be consistent across the levels.

6. Students' learning outcomes should match to the assessment outline.

7. It is important that assessment aligns with course objectives.

8. Assessment should be structured to evaluate the students' level of achievement in various language components.

9. Assessment should help to analyze the suitability of the included components.

10. Engaging students in peer- and self-assessment is a good idea.

11. Teacher should know how to make use of students' results for their improvement.

12. Teacher should use a list of specifications while planning an assessment.

\begin{tabular}{|c|c|c|c|}
\hline NA & A & D & SA \\
\hline NA & A & D & SA \\
\hline NA & A & D & SA \\
\hline NA & A & D & SA \\
\hline NA & A & D & SA \\
\hline NA & A & D & SA \\
\hline NA & A & D & SA \\
\hline NA & A & D & SA \\
\hline NA & A & D & SA \\
\hline NA & A & D & SA \\
\hline NA & A & D & SA \\
\hline NA & A & D & SA \\
\hline
\end{tabular}

